\title{
Pt-Rh-Pd Alloy Group Gauze Catalysts Used for Ammonia Oxidation
}

\author{
Liu Xin ${ }^{1,2}, \quad$ Han Yongqiang ${ }^{2}$, Jia Husheng ${ }^{1}$ \\ ${ }^{1}$ Taiyuan University of Technology, Taiyuan 030024, China, ${ }^{2}$ China National Offshore Oil Taiyuan Precious Metals Co., Ltd, Taiyuan 030006, \\ China
}

\begin{abstract}
Pt-Rh-Pd alloy gauze catalysts used for ammonia oxidation were studied to improve the efficiency in the industry of nitric acid. According to the character of ammonia oxidation, such catalysts were divided into three main reaction zones. Pt-Rh-Pd alloy group gauzes were installed in dual pressure ammonia oxidation apparatus with the diameter of $3880 \mathrm{~mm}$, which was operated under a pressure of $0.35 \mathrm{MPa}$. Based on the characterization by FESEM and EDS, the catalysis mechanism of the gauze catalysts was proposed. Through the calculation of oxidation efficiency, the catalysis effect is improved by $1 \%$ with the Pt-Rh-Pd alloy gauzes, where the involvement of Pd endows the catalyst with catalysis, catchment, solid solution and second catalysis. As the result, the cost is reduced by $30 \%$ and the loss of Pt is decreased from $120 \mathrm{mg}$ to $70 \mathrm{mg}$. Thus, the catalysts show the great potential for future industrial applications.
\end{abstract}

Key words: Pt-Rh-Pd alloy group gauzes; catalysts; ammonia oxidation

Today the worldwide capacity of the manufacture of nitric acid by the Ostwald process is over 100 million tons per year $^{[1]}$. To prepare nitric acid by ammonia oxidation, Pt-Rh or Pt-Rh-Pd alloy has been used as catalyst gauzes with the pressure of $1 \sim 10$ atm $(101 \sim 1010 \mathrm{kPa})$ and temperature of $800 \sim 950{ }^{\circ} \mathrm{C}$. However, Platinum oxide, $\mathrm{PtO}_{2}$, which is volatile, was formed on the catalyst surfaces and caused a loss in platinum between $0.05 \sim 0.3 \mathrm{~g}$ per ton of produced nitric $\operatorname{acid}^{[1]}$. For the dual pressure apparatus, a principal process for manufacturing nitric acid, the platinum loss ratio of the gauzes is around $0.12 \mathrm{~g}$. In order to recover the lost platinum, catchment gauzes made of palladium-based alloy were introduced into the ammonia oxidation reaction chamber and installed directly beneath the catalyst gauzes ${ }^{[2-5]}$. As a result, $\mathrm{PtO}_{2}$ is caught by a high palladium content alloy with the reaction of $2 \mathrm{Pd}+\mathrm{PtO}_{2}=\mathrm{Pt}+2 \mathrm{PdO}^{[6]}$. But the captured platinum would lose catalysis effect, leading to reduced efficiency in platinum utilization. In recent years, multi-effect group Pt-based alloy gauzes have been used in ammonia oxidation apparatus, which combined catalyzing, catching, solid solution, and second catalyzing effects.

Platinum or Platinum rhodium catalyst gauze was applied in producing nitric acid and hydrocyanic acid since $1909^{[1]}$. The catalyst gauze experienced the leap and change from woven gauze to knitted gauze, weft knitted gauze to warp knitted gauze, Pt-Rh and Pt-Rh-Pd alloy unit gauze to Pt-Rh-Pd alloy group gauzes. The dual pressure apparatus always used 7 8 warp knit unit gauze as the catalyst before the invention of group gauzes. However, the warp knit gauze, Pt-Rh-Pd alloy group gauzes and the principle of catalysis that took place in Pt-Rh-Pd alloy group gauzes have been rarely reported. In the present paper, the structure and principle in Pt-Rh-Pd alloy group gauzes were discussed, based on the morphology and economic value observed with pressure of $3 \sim 4 \times 10^{5} \mathrm{~Pa}$ pressures and temperature of $830 \sim 870{ }^{\circ} \mathrm{C}$ in the dual pressure apparatus.

\section{Experiment}




\subsection{Structure of the catalyst gauze}

The structures of the woven gauze, weft knitting gauze and warp knitting gauze are shown in Fig.1. Wires of weft and warp simply crossed with each other in Fig.1a. The woven gauze was designed as rectangle grid, proportional spacing, and two-dimensional. Thus, active surface was wasted as a result of this woven structure.

The feature of weft knitted gauze was open circled, where wires of every row did not cross, as shown in Fig. 1b. Though it is stretchable, mechanical stability is not good. Wire breaking will cause stitches dropping. On the other hand, warp knitted gauze was closed circled and wires roundly crossed with each other, as shown in Fig. 1c. When a wire breaks, wires will tie around the broken. So it has good mechanical stability because of no stitches dropping. Warp knitted gauze is in fine close stitch and its stitch is adjustable, which fully shows the advantage in technology, and fully meets the needs of high efficiency and quality catalyst gauze for nitric acid production.

Pt-Rh-Pd alloy group gauzes were divided into three reaction zones according to the character of ammonia oxidation in which the catalytic reaction of ammonia and air mixture took place from top to bottom, as shown in Fig. $2^{[1]}$. The zone 1 was defined as the main reaction zone, loading $70 \% \sim 80 \%$ of oxidation. The zone 2 was defined as the auxiliary reaction zone, which loaded $20 \% \sim 25 \%$ of oxidation. The zone 3 was defined as the additional reaction zone, loading 5\% 10\% of oxidation. The content of platinum gradually diminished, while the content of palladium increased from zone 1 to zone 2 for Pt-Rh-Pd alloy group gauzes. At the same time, the knitting structure was still adopted by the warp knitted gauze.

\subsection{Experimental procedure}

Pt-Rh-Pd alloy group gauzes were installed in dual pressure ammonia oxidation apparatus, which was operated at a pressure of $0.35 \mathrm{MPa}$ and temperature of $870{ }^{\circ} \mathrm{C}$. The concentration of ammonia in the ammonia-air mixture was $10.5 \%$ to $11 \%$, and the catalyst gauze consisted of thirteen sheets of Pt-Rh-Pd alloy of warp knitted gauze. This ammonia oxidation apparatus was used for manufacturing nitric acid with the capacity of 150 thousand tons per year. The diameter of oxidation apparatus was $3880 \mathrm{~mm}$. The zone 1 catalyst gauze consisted of five sheets of platinum-(88\% 95\%) rhodium-(5\% 15\%) palladium alloy, the zone 2 catalyst gauze consisted of three sheets of platinum-(48\% 76\%) rhodium-(5\% 10\%) palladium alloy, and the zone 3 catalyst gauze consisted of five sheets of platinum-(5\% 20\%) rhodium-(3\% 7\%) palladium alloy. The diameter of the alloy wire was between 0.05 and 0.09 $\mathrm{mm}$. Generally, the diameter of the alloy wire and the alloy content were adjusted according to the specific surface area of catalyst, the parameter of ammonia oxidation apparatus, air condition, and so on.
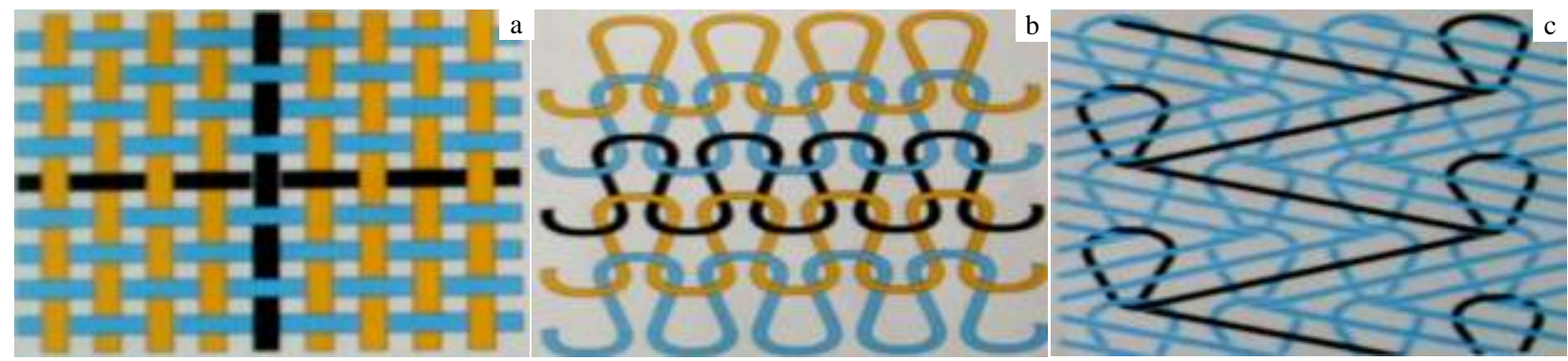

Fig.1 Structures of the woven gauze (a), weft knitted gauze (b), and warp knitted gauze (c)

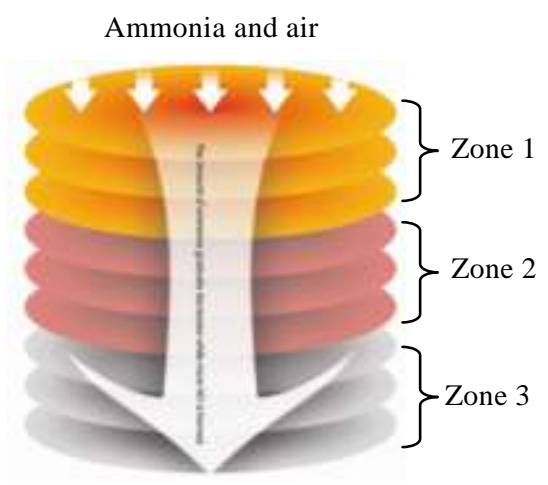

Fig.2 Installation structure of Pt-Rh-Pd alloy group gauzes
Pt-Rh-Pd alloy group gauzes were operated for 6 months (Fig.3). The topography of samples taken in zone 1 to zone 3 were characterized by field emission scanning electron microscopy (FESEM) and EDS analysis (Fig.4).

\section{Results and Discussion}

\subsection{Morphology and structure of new gauze}

New gauzes were produced with the clean and smooth alloy wire. After the operation of the new gauzes for about $24 \mathrm{~h}$, the topography of wire surface become cauliflowerlike ${ }^{[1]}$. This phenomenon shows that catalytic activity is fully developed because of the increase in the specific surface area under the condition of pressure of 0.35 


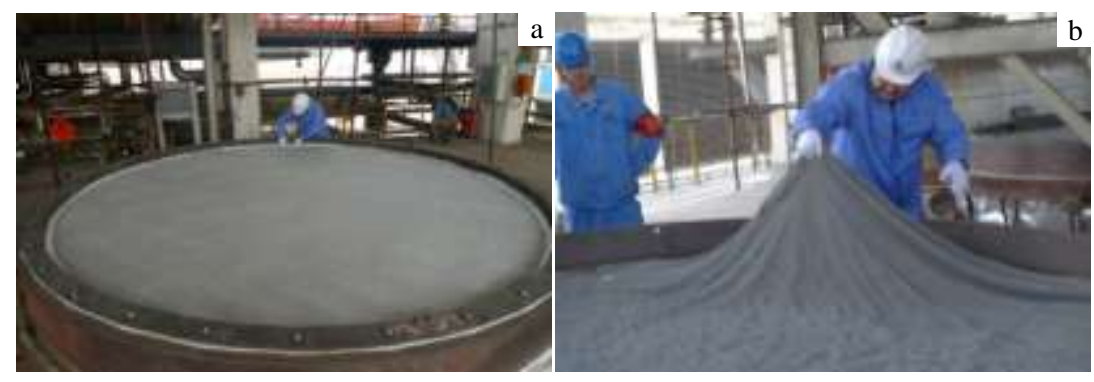

Fig.3 Catalysts before (a) and after (b) used in the ammonia oxidation apparatus

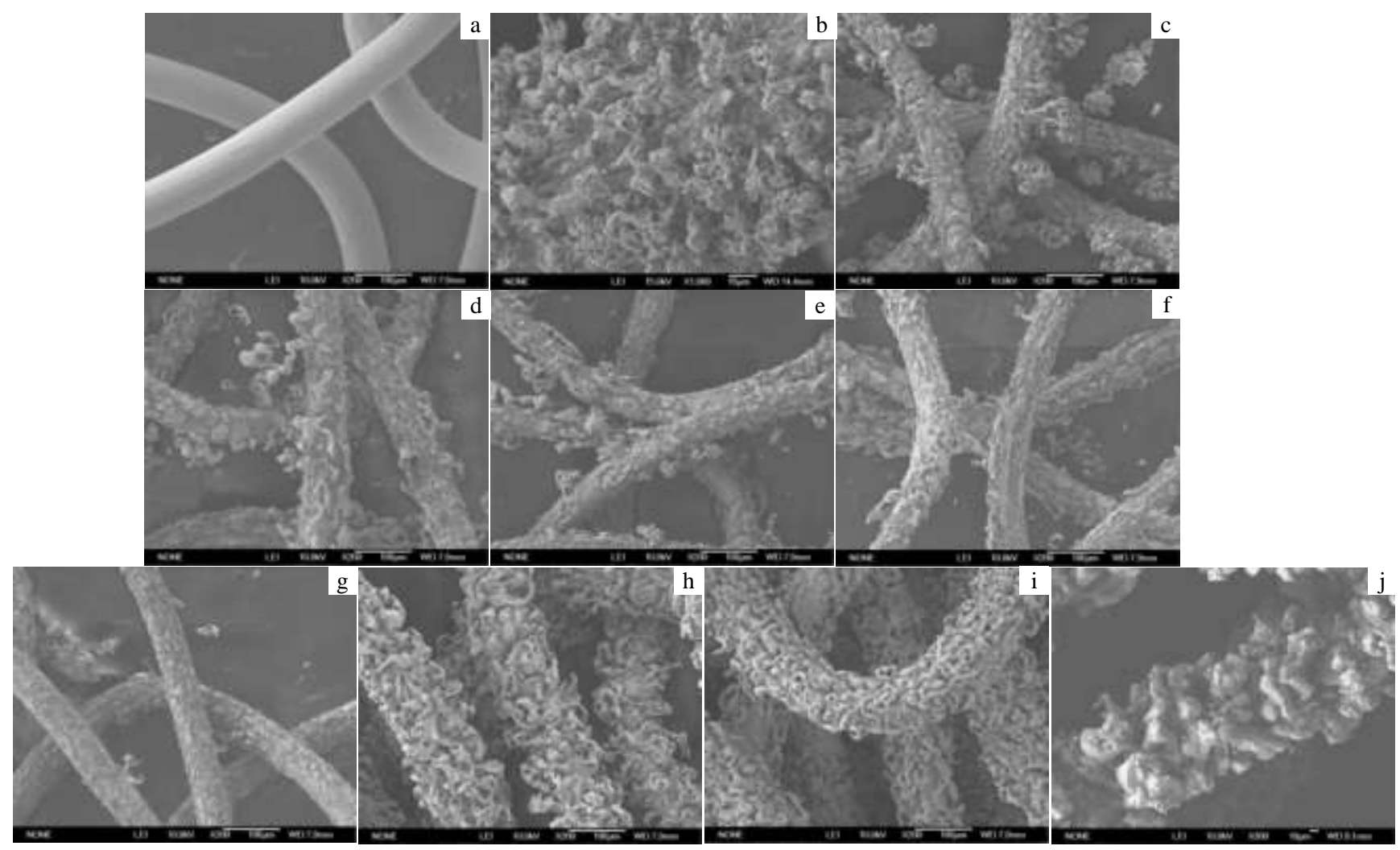

Fig.4 Morphologies of the sample surface by FESEM in the downstream direction: (a) new wire; (b) the wire after used for $24 \mathrm{~h}$; (c $\sim$ g) the wire in zone 1 ; $(\mathrm{h}, \mathrm{i})$ the wire in zone 2 ; $(\mathrm{j})$ the wire in zone 3

$\mathrm{MPa}$ and temperature of $870{ }^{\circ} \mathrm{C}$. During the ammonia oxidation process, the volatile platinum oxide $\left(\mathrm{PtO}_{2}\right)$ and palladium oxide $(\mathrm{PdO})$ and the nonvolatile rhodium oxide $\left(\mathrm{Rh}_{2} \mathrm{O}_{3}\right)$ are produced in the platinum-palladium-rhodium catalyst gauzes. The mass loss in the zone 1 of catalyst gauzes results mainly from volatilization of platinum as $\mathrm{PtO}_{2}$, because of high $\mathrm{Pt}$ content in this zone. So the wires of zone 1 become thinner.

The zone 2 catalyst contains a high amount of palladium, which could react with platinum oxide to form Pt-Pd solid solution alloy in the gauzes' surface ${ }^{[6]}$. The captured platinum continues to catalyze for keeping high oxidation rate. This method can not only decrease the platinum content, but also increase the platinum utilization. At the same time, the wires of zone 2 become thick to increase the specific surface area. Characterization of the gauzes shows very different structures on the surfaces of the zone 1 and zone 2 gauzes. Fig.4i and $4 \mathrm{j}$ show the interfacial structure of platinum (palladium) solid solution crystals.

The zone 3 catalyst contains the highest amount of palladium, mainly used for absorbing the platinum oxide, where the captured platinum continues to catalyze the ammonia oxidation.

\subsection{Principle of Pt-Rh-Pd alloy group gauzes}


There is a special percentage of $\mathrm{d}$ electronic orbit for platinum, rhodium and palladium. Because of different temperatures of the oxidation formation, it is thought that platinum has higher excellent catalytic activity. The volatilization temperature of platinum oxide, palladium oxide and rhodium oxide is about 380 400, 877, and $1113 \sim 1127{ }^{\circ} \mathrm{C}{ }^{[7]}$, respectively. Generally, these oxides could inhibit the catalytic reaction, while, platinum always presents a new surface after the platinum oxide is volatilized.

The catalytic process of gauzes is cyclic, with catalytic activity induction, active site establishment, activity maintenance and activity declination. EDS result indicates that the main component of frame is rhodium and rhodium oxide after the platinum oxide is volatilized, as shown in Fig.5a. The frame is washed away by the ammonia and air mixture (0.35 MPa pressure) with the progress of reaction. The new surface of platinum appears and the new active site was established, as can be judged from Fig.5b. The cyclic process of catalyzing is sustainably operated.

\subsection{Economic advantage of Pt-Rh-Pd alloy group gauzes}

The mass of Pt-Rh alloy gauze is about $52000 \mathrm{~g}$, including $48400 \mathrm{~g}$ platinum and $3600 \mathrm{~g}$ rhodium. The mass of Pt-Rh-Pd alloy group gauzes is about $53000 \mathrm{~g}$ including $33000 \mathrm{~g}$ platinum, $2000 \mathrm{~g}$ rhodium, and $18000 \mathrm{~g}$ palladium. The purchasing prices fell sharply, because of a large amount of added palladium. According to the international prices of precious metals, customer purchase costs fell more than $30 \%$. Platinum consumption decreased from $120 \mathrm{mg}$ to $70 \mathrm{mg}$ per ton of nitric acid in the running process of ammonia oxidation. At the same time, the oxidation rate increases by $1 \%$ and the oxidation rate in the period is sustained and stable in Fig.6.

$\mathrm{NH}_{3}$ and $\mathrm{O}_{2}$ could react to generate $\mathrm{NO}, \mathrm{N}_{2}$ and $\mathrm{N}_{2} \mathrm{O}$ by Pt-Rh-Pd alloy group gauzes (Fig.7), according to the
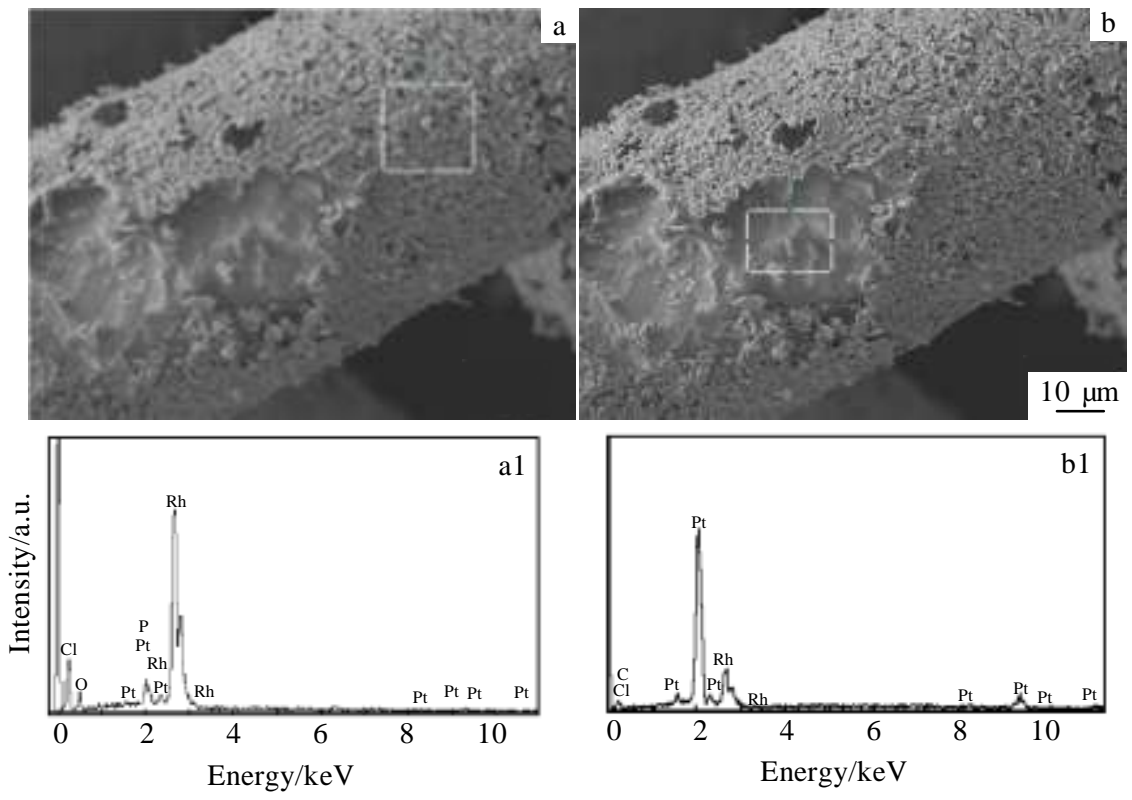

Fig.5 Morphologies (a, b) and EDS spectra (a1, b1) of the sample after using $180 \mathrm{~d}$ : (a) rhodium and rhodium oxide and (b) new surface of platinum appears

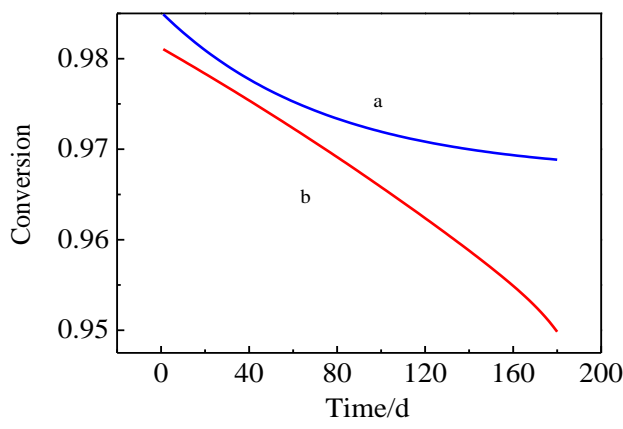

Fig.6 Oxidation rate analysis in comparison with the same unit for a $180 \mathrm{~d}$ period (a-Pt-Rh-Pd alloy group gauzes; bPt-Rh alloy gauze)

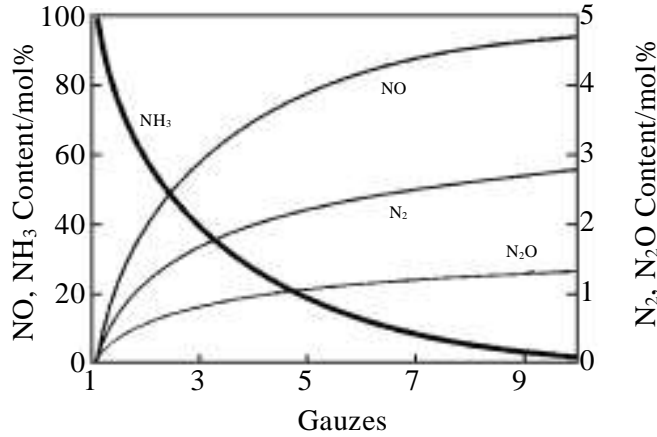

Fig.7 Concentration distribution over catalyst 
following reactions. The author hopes to get more NO by gauze, and then the Pt-Rh-Pd alloy group gauzes oxidation rate is increased by $1 \%$ compared with the $\mathrm{Pt}-\mathrm{Rh}$ alloy gauze oxidation rate.

$$
\begin{aligned}
& \mathrm{NH}_{3}+1.25 \mathrm{O}_{2} \Rightarrow 1.5 \mathrm{H}_{2} \mathrm{O}+\mathrm{NO} \\
& \mathrm{NH}_{3}+1.75 \mathrm{O}_{2} \Rightarrow 1.5 \mathrm{H}_{2} \mathrm{O}+\mathrm{NO}_{2} \\
& \mathrm{NH}_{3}+0.75 \mathrm{O}_{2} \Rightarrow 1.5 \mathrm{H}_{2} \mathrm{O}+0.5 \mathrm{~N}_{2} \\
& \mathrm{NH}_{3}+\mathrm{O}_{2} \Rightarrow 1.5 \mathrm{H}_{2} \mathrm{O}+0.5 \mathrm{~N}_{2} \mathrm{O} \\
& \mathrm{NH}_{3} \Rightarrow 1.5 \mathrm{H}_{2}+0.5 \mathrm{~N}_{2} \\
& \mathrm{NH}_{3}+1.5 \mathrm{NO} \Rightarrow 1.5 \mathrm{H}_{2} \mathrm{O}+1.25 \mathrm{~N}_{2}
\end{aligned}
$$

\section{Conclusions}

1) Pt-Rh-Pd alloy group gauze catalysts have the circulation function of catalysis, absorption, solid solution and catalysis by changing the alloy composition, knitting structure, wire diameter.

2) The catalysis effect is improved by $1 \%$ with the Pt-Rh-Pd alloy gauzes, where the involvement of $\mathrm{Pd}$ endows the catalyst with catalysis, catchment, solid solution and second catalysis. As the result, the cost is reduced by $30 \%$ and the loss of Pt is decreased from $120 \mathrm{mg}$ to $70 \mathrm{mg}$.

3) This design will help to decrease the amount and increase utilization of $\mathrm{Pt}$ in the nitric acid industry. The oxidation rate can be improved and the cost can be cut down dramatically (30\%).

\section{References}

1 Franz Sperner, Wolfgang Honhmann. Platinum Metals Rev[J], 1976, 20(1): 12

2 Zyuzin S V, Barelko V V, Chemyshov V I et al. h k n Patent 1573594[P]. 1988

3 Brustian E A, Vasina S Y, Lazaricheva I V et al. Russian Patent, 1807608[P], 1991

4 Loboyko O Ya, Gryn G I, Trusov N V et al. 94 Report of Int Meeting, Rare and Precious Metals $[\mathrm{C}]$. Donetsk: Rare and Precious Metals, 1994: 40

5 Gryn G I, Trusov N V, Loboyko O Ya. 93 Activation and Regeneration of the Catalyst on the Basis of Platinum and Its Alloys during Oxidation of Ammonia and Oxidizing Ammonolysis of Methane, Catalytic and Mass Transfer Processes under Pressure in Inorganic Substances Technology [C]. Kharkov: Osnova, 1993: Section 9

6 Ning Yuantao, Yang Zhenfen, Zhao Huaizhi et al. Platinum Metals Rev[J], 1995, 39(1): 19

7 Yang Zhenfen, Ning Yuantao, Zhao Huaizhi. Journal of Alloys and Compounds[J], 1995, 218: 51

\title{
氨氧化 Pt-Rh-Pd 合金组合网催化剂
}

\author{
刘 欣 ${ }^{1,2}$, 韩勇强 ${ }^{2}$, 贾虎生 ${ }^{1}$ \\ (1. 太原理工大学, 山西 太原 030024)
}

(2. 中海油太原贵金属有限公司，山西 太原 030006)

\begin{abstract}
摘 要: 通过研究氨氧化用 Pt-Rh-Pd 合金网催化剂, 旨在为了提高工业硝酸生产的效率。按照氧化炉中氨氧化反应的特性, 将该催化 剂分为 3 个反应区域。Pt-Rh-Pd 合金组合网催化剂安装在氨氧化双加压机组中, 其直径 $3880 \mathrm{~mm}$ 、操作压力 $0.35 \mathrm{MPa}$ 。根据 FESEM 和 EDS 对表面形貌的研究, 提出了催化网的反应机理。通过氧化率计算, 使用 Pt-Rh-Pd 合金组合网氧化率提高了 $1 \%$ 。Pd 的掺入使催 化剂兼具催化、捕集、固溶和再催化的作用。同时, 采购成本降低 $30 \%, \mathrm{Pt}$ 损耗由 $120 \mathrm{mg}$ 降低至 $70 \mathrm{mg}$ 。因此, 该催化剂具有广泛的 应用前景。
\end{abstract}

关键词: Pt-Rh-Pd合金组合网; 催化剂; 氨氧化

作者简介: 刘 欣, 男, 1982 年生, 博士生, 太原理工大学材料学院, 山西 太原 030024, 电话: 0351-7028182, E-mail: 1826liuxin@163.com; liuxin47@cnooc.com.cn 